\title{
Neural Network Model Identification and Advanced Control of a Membrane Biological Reactor
}

\author{
Raafat Alnaizy, Ahmed Aidan, Noor Abachi and Nabil Abdel Jabbar
}

Department of Chemical Engineering, American University of Sharjah, PO Box 26666, Sharjah, UAE

\begin{abstract}
System identification with different input-output structures, for a membrane biological reactor (MBR), was performed using artificial neural networks (ANN) black-box modeling. The ANN models were able to capture the dynamic flux experimental literature data. Sensitivity analyses were applied on the ANN models to quantify the effects of variation in the process inputs (backwash pressure, vacuum pressure, backwash and vacuum time) on the process output (flux rate. Sensitivity analysis was applied on the developed NN in order to find the optimum backwash scheduling. The maximum flux was attained at around $165\left(\mathrm{~L} / \mathrm{m}^{2}\right.$.day) that corresponded to an optimum vacuum-to-backwash time ratio of 10 minutes vacuum to 2 minutes backwash. Advanced control strategy using neuro-model predictive control (NNMPC) methodology was applied to control the MBR system. The NN-MPC parameters were tuned to attain an optimum performance. The NN-MPC was efficient in tracking the flux set-point changes by adjusting vacuum-to-backwash time ratio within the operation constraints.
\end{abstract}

Keywords: Backwash, flux, optimization, sensitivity analysis, fouling control, wastewater treatment, neuro-model predictive control.

\section{INTRODUCTION}

The high efficiency of MBRs in producing a highquality effluent makes it an attractive alternative for municipal and industrial wastewater treatment. However, the presence of microorganisms and membrane fouling contributes to the instability of such systems. Stability of any dynamic multivariable system is a challenging problem due to the complexity of interactions and nonlinearity.

The main source of nonlinearity is attributed to the nonlinear interactions between the biomass, substrate, and membrane. The high nonlinear interactions facilitate membrane fouling [1-5]. Fouling affects the net permeate production rate due to the rapid permeate flux decline. Backwashing is one of the techniques utilized to clean and regenerate the membrane; nevertheless, switching operation modes between vacuum and backwash leads to unstable permeate production [6, 7]. To maintain a stable permeate flow, the MBR is operated at the instantaneous flux. The instantaneous flux is the maximum flux attained during the process start-up when the membrane is clean and no fouling is observed. Operating at this flux requires frequent backwashing which increases the operation cost and may rupture the membrane and/or pump.

Artificial Neural Networks (ANN) has been widely used during the last decade for modeling process

*Address correspondence to this author at the Department of Chemical Engineering, American University of Sharjah, PO Box 26666, Sharjah, UAE; Tel: +971 6515 2817; Fax: +971 6515 2979; E-mail: nabdeljabbar@aus.edu dynamics. It has also spread over diverse branches of membrane technology. Many researchers are utilizing ANNs in modeling, predicting, simulating, or controlling various membrane separation/purification processes, such as microfiltration (MF) [8], ultrafiltration (UF) [9], nanofiltration [10], zeolite membrane [11], reverse osmosis (RO) [12], membrane bioreactor, and submerged membrane bioreactor [13]. The widespread application of ANN analysis to membrane processes is due to its ease in implementation, accuracy in understanding the process nonlinear dynamics (i.e., fouling) and an effective computing tool in membrane modeling $[14,15]$.

Many attempts were made to control MBRs [16-23]. The challenge of MBRs control arises from the high nonlinearity and complexity of the process as mentioned above.

Thus, poor control performance may lead to unstable operations and insufficient permeate production. Primarily, implementing a conventional linear PID controller to a nonlinear process gives unsatisfactory servo and regulatory performance responses to any change in the process operating parameters [24]. Hence, tuning a linear PID controller with a nonlinear process at one operating condition may destabilize it at other operating conditions; such behavior is referred to as bifurcation [25, 26], in which the system may be stable at a certain operation point but a slight change may result in a jump to an unstable operation region. Bifurcation in some nonlinear systems depends on a range of one parameter to be stable. If the parameter deviates from its range, the 
system becomes either unstable or reaches a new equilibrium point which lies above or below the acceptable operating ranges within a plant. An example on bifurcation behavior in a bioreactor is the biodegradations of dissimilar substrates due to the variation of the dilution rate [27].

Therefore, an advanced control strategy is essential to stabilize the MBR and optimize its performance. Model predictive control (MPC) is a viable option for controlling nonlinear processes due to its unique features in tracking the set-point and overcoming the plant model mismatch [28]. However, MPC mandates that system dynamic model is explicitly used in calculating control moves necessary to achieve the target set-point. Such requirement poses a great challenge in applying MPC on complex processes, such as MBRs, since their dynamic models are very complex and computationally expensive. Therefore, artificial intelligent techniques such as neural network, fuzzy logic, and genetic algorithms were proposed to tackle such dynamic systems.

Artificial intelligent techniques were investigated by several researchers to control membrane fouling. A type 2-fuzzy logic controller was implemented by Galluzzo et al. [27] to stabilize the MBR. Afterwards, the MBR performance using fuzzy logic was compared with that of a conventional linear PID controller. Type 2fuzzy logic demonstrated a better performance; however, some oscillations occurred and Neural Network was recommended as an alternative. Artificial Neural Networks (ANN) has been widely used during the last decade for modeling process dynamics. It has

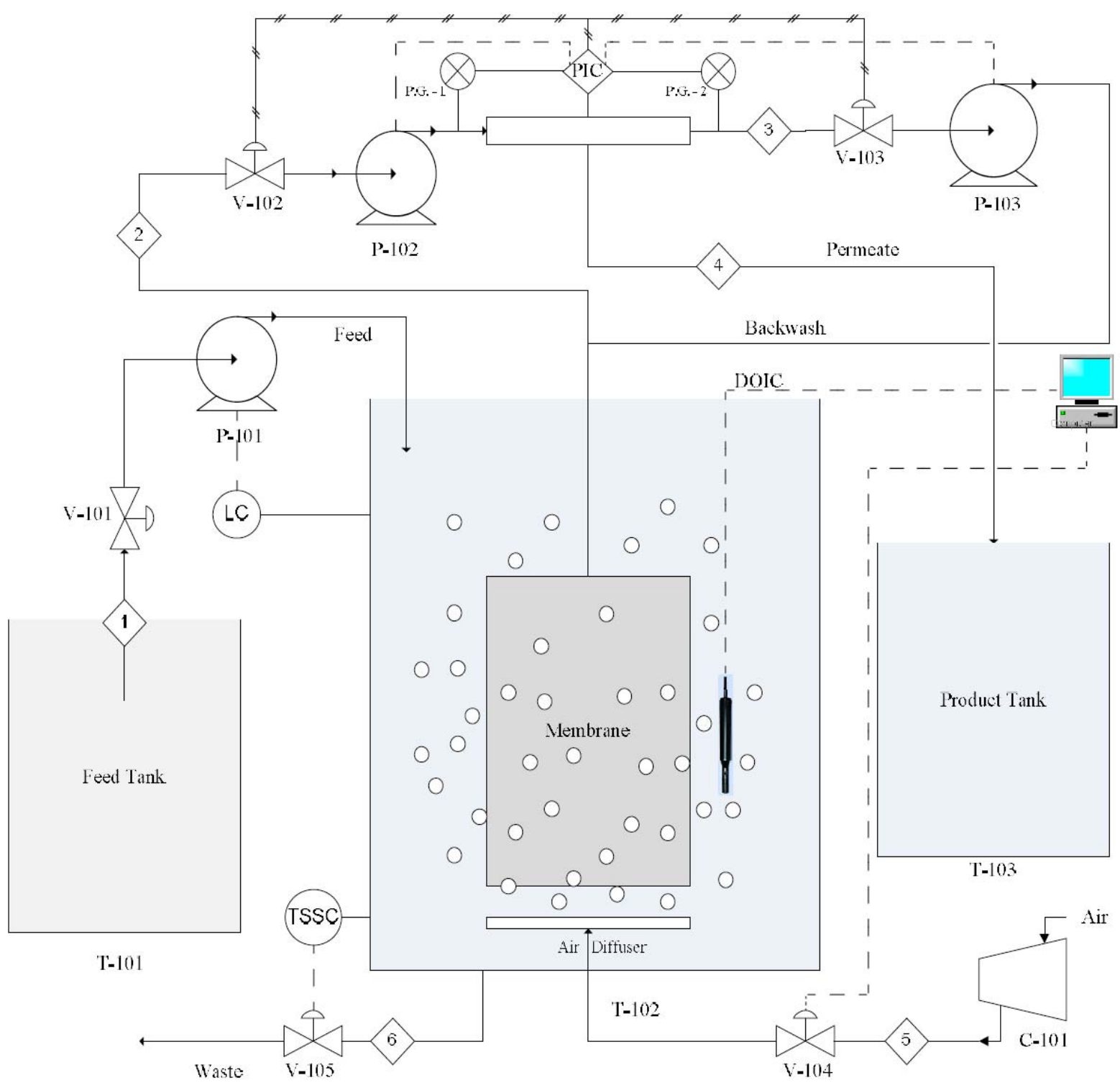

Figure 1: A schematic diagram of MBR [29]. 
also spread over diverse branches of membrane technology.

The objective of this work is to present an ANN modeling scenarios for different input-output structures of the MBR. In the second part, the developed ANN models will be augmented in an NN-MPC control algorithm for continuous output prediction and inversion of process dynamic matrix. This control strategy calculates the necessary control moves in order to attain a target flux of the membrane for the purpose of optimizing its performance and control membrane fouling. The performance of this proposed advanced artificial control algorithm will be demonstrated.

\section{PROCESS DESCRIPTION}

A schematic diagram of the process is shown in Figure 1. The bioreactor is made of acrylic plate with dimensions $(\mathrm{L} \times \mathrm{W} \times \mathrm{H})$ of $15 \times 3 \times 30 \mathrm{~cm}$. It employs a flat-sheet-type ceramic membrane with a pore size of $0.2 \mu \mathrm{m}$ and a total size area of $0.048 \mathrm{~m}^{2}$ (from all sides). A full description of the feed composition, materials, process operation and basic controls can be found in Alnaizy et al., [29].

\section{ARTIFICIAL NEURAL NETWORK (ANN)}

Artificial Neural Network (ANN) is used in biological processes as a modeling tool for information processing. It is a parallel mathematical computational model comprises compactly of interconnected adaptive processing units. The adaptive nature of this network makes it appropriate for learning the behavior of both static and dynamic systems. This feature makes such computational models very appealing in the application domains where there is incomplete understanding of the process to be solved while a large set of training data is available. The ANN model is trained by adjusting the connection weights of the network and is validated. The ANN architecture may be classified according to either the number of layers (Single or multilayer) or the way the neurons are connected (Feed forward or recurrent). Multilayer neural network is used as a function approximator in a continuous multivariable system with definite structure and parameters. The neuron is the basic building block of the ANN. It consists of connecting weights, summation/multiplication operations, bias, and activation functions. The weights are adjusted by a training algorithm through minimizing the error between the predicted and target variable. The bias is used to shift the activation function allowing a better network training. The activation function is used to introduce nonlinearity into the network, and also to limit the amplitude of the neuron output. Back propagation is the most common training algorithm. Its basic network architecture consists of a two layer network with a sigmoid function in the first layer and linear function in the second.

\section{MODEL PREDICTIVE CONTROL (MPC)}

The MPC calculates the control moves through manipulation of predetermined variables based on the response of the controlled variables in the course of an explicit dynamic model. The control moves force the controlled variables to follow a predefined trajectory to

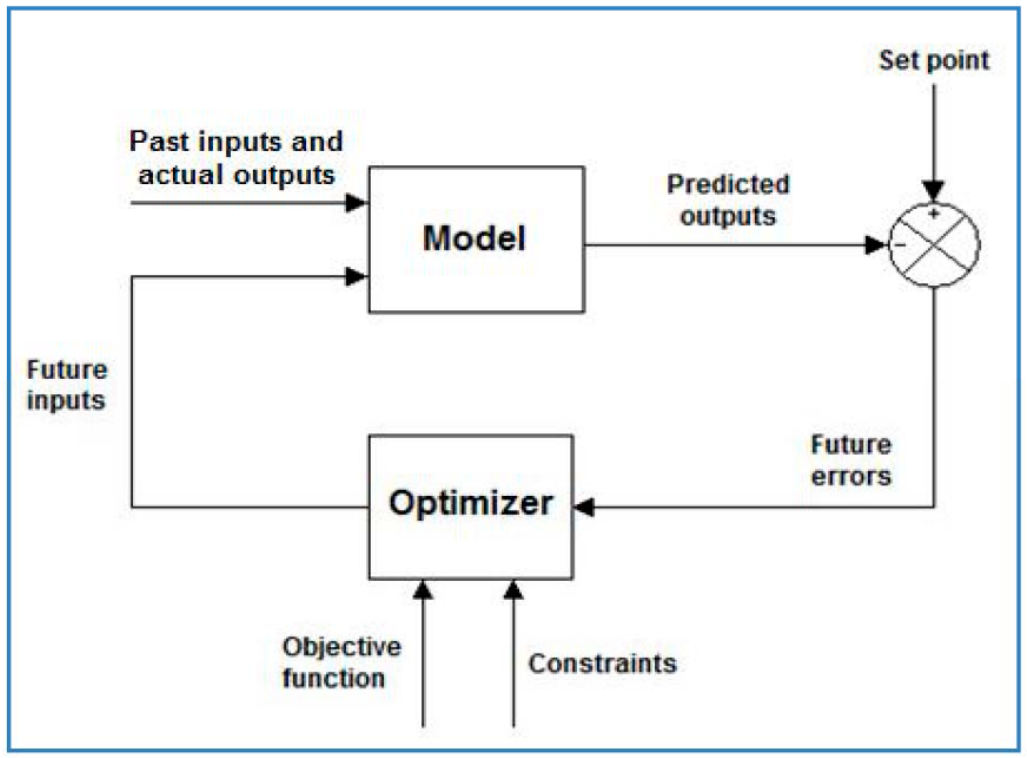

Figure 2: Basic MPC structure [28]. 
track the target or set-point. The controller moves are performed by the current measurements and future predictions. The basic structure of MPC is shown in Figure 2. More details are available in [28].

The MPC formulation is based on minimizing the following cost functions:

$$
\begin{aligned}
& \min _{\Delta u}\left[\sum_{i=1}^{P}(\text { Prediction }- \text { setpoint })^{2}+\sum_{l=1}^{M}(\text { Control effort })^{2}\right] \\
& \min _{\Delta u} J=\sum_{i=1}^{N}\left(E_{i}^{T} Q E_{i}+\Delta u_{i}^{T} R \Delta u_{i}\right)
\end{aligned}
$$

Where: $M$ is the control horizon

$N$ is the model horizon

$P$ is the prediction horizon

$Q$ is the weighting matrix for predicted errors $(Q>0)$

$R$ is the weighting matrix for control moves $(R>0)$

The first term in Equation (2) represents the setpoint tracking through minimizing the error $(E)$ between the set-point and process output, while the second term is defined in terms of input control moves, $\Delta u$. This optimization problem is solved using sequential quadratic programming, which produces a solution constrained within the process input operating ranges. Tuning parameters for MPC are selected based on the Model Horizon $(N)$, sampling time $(\Delta t)$, Control Horizon $(M)$, Prediction Horizon $(P)$, and Weighting matrices $(Q$ and $R$ ). The model horizon and sampling period are selected between 30 and 120 or according to the following correlation.

$N \cdot \Delta t \geq$ open-loop settling time

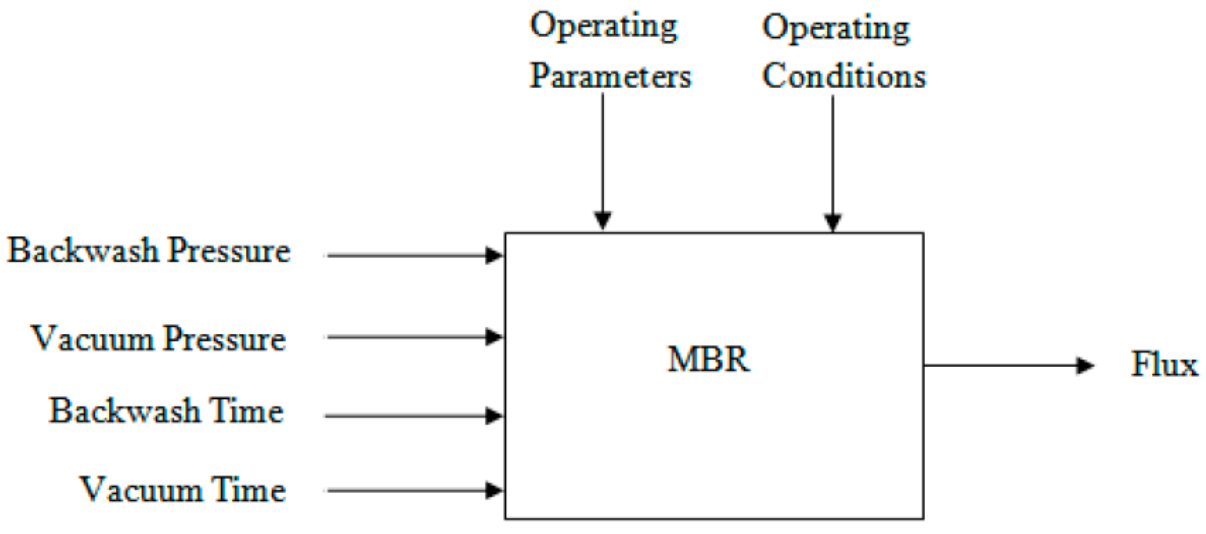

A typical range of the control horizon is set between 3 and 20. However, the MPC implements the first control move out of the $M$ calculated moves. The prediction horizon is designed to be greater than the process output time delay, in order to provide enough time for future output prediction and smoother control. Moreover, a sufficient large prediction horizon is selected to minimize the aggressiveness of the controller action. In other words, increasing $P$ results in less aggressive controller action. As a result, the prediction horizon is set to equal model horizon plus control horizon. More emphasis is placed on the outputs by further increasing the diagonal elements. It follows from Equation (2), if minimizing the error or the output scaling is more important, larger $Q$ diagonal elements are selected. Conversely, if input scaling is more important, larger $R$ diagonal elements are selected. If the variables are in the same range, the weighting matrices are set to the identity matrix [14].

\section{NEURO MODEL PREDICTIVE CONTROL (NN-MPC)}

The NN-MPC is a subclass of model predictive controllers. It is an advanced control strategy based on a nonlinear neural network model for prediction. NNMPC implementations require a large data set and tuning several controller parameters. Prior to simulating the NN-MPC, plant identification is performed and the controller parameters are tuned. Plant identification is achieved by identifying the structure of the nonlinear neural network, the plant model, and the input/output data set. The input/output data set may be either imported if a large data set is available or generated through the predefined plant model. After accepting the data, the neural network is trained, validated, and tested according to the selected learning algorithm. Subsequently, the best NN training performance is chosen based on the regression plots. The NN-MPC 
block diagram is readily available in MATLAB NN Predictive Control, Neural Network Toolbox, 2011 [30].

\section{RESULTS AND DISCUSSION}

The selection of process variables is based on selecting the variables that may be measured experimentally and gives a direct indicator on membrane fouling. Figure 3 depicts the process block diagram with the selected input/output variables.

Extension to an earlier work done by Aidan et al., [15], artificial neural network modeling is performed here by different ANN modeling scenarios connecting the multi inputs to achieve the single output. The different ANN models are trained, validated, and tested. Consequently, results are compared by the regression plot between the ANN model output and experimental output variable.

\section{ANN Scenario 1}

The objective is to obtain an ANN model between:
1) Ratio and backwash pressure, ANN1

2) Ratio and vacuum pressure, ANN2

3) Both backwash pressure, vacuum pressure and flux, ANN3

The predicted backwash pressure from the ANN1 model (shown in Figure 4) is validated with that obtained experimentally, see Figure 7. The overall regression between the ANN1 predicted output and target is verified with training, validation, and testing regressions of $0.961,0.955$, and 0.955 , respectively.

ANN2 trains the vacuum-to-backwash time ratio (input variable) to predict the vacuum pressure $P_{v a c}$ (output variable). The training is performed by minimizing the error between the predicted $P_{v a c}$ from ANN2 and the experimental $P_{\text {vac }}$ (target variable). ANN2 training is stopped utilizing 692 epochs. The predicted vacuum pressure from ANN2 model is validated with that obtained experimentally as shown in Figure 6 . Also, the overall regression between the

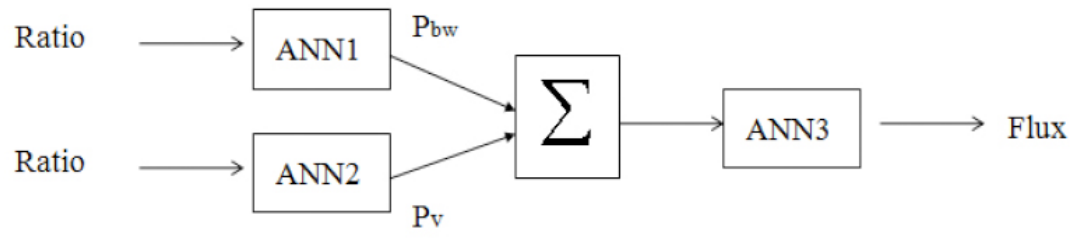

Figure 4: ANN model structure for scenario 1.

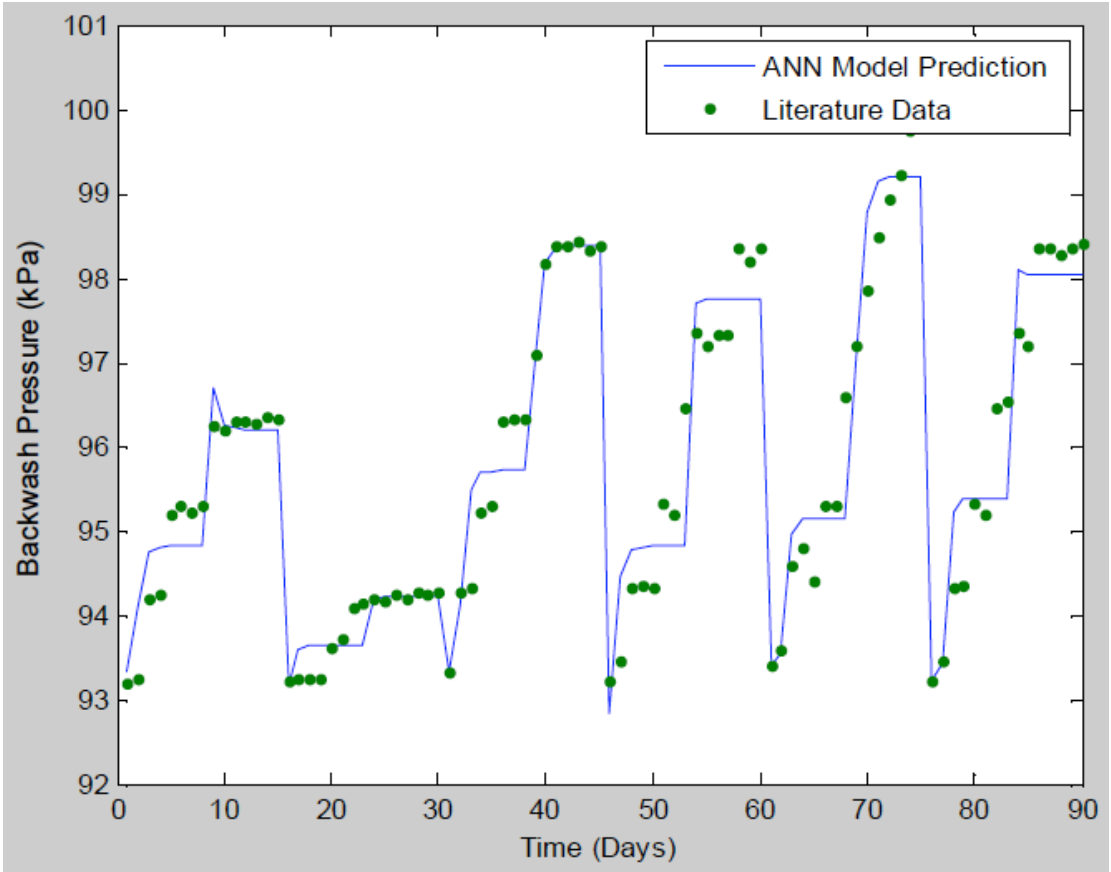

Figure 5: ANN predicted and experimental $\mathrm{P}_{\mathrm{bw}}$ of ANN1 - scenario 1. 
ANN2 predicted output and target is verified with training, validation, and testing regressions of 0.961 , 0.955 , and 0.955 , respectively.

ANN3 trains two predicted outputs from ANN1 and ANN2 $\left(P_{b w}, P_{v a c}\right)$ to predict the flux. Therefore, ANN3 utilizes two inputs to predict a single output. The training is performed by minimizing the error between the predicted flux from ANN3 and the experimental flux (target variable). ANN3 training is stopped utilizing 54 epochs. The predicted flux from ANN3 model is validated with that obtained experimentally in Figure 7. The overall regression between the ANN3 predicted output and target is verified with training, validation, and testing regressions of $0.988,0.989$, and 0.989 , respectively. Clearly, the ANN models were able to capture most of the data points and gives good match with actual process dynamics for backwash pressure

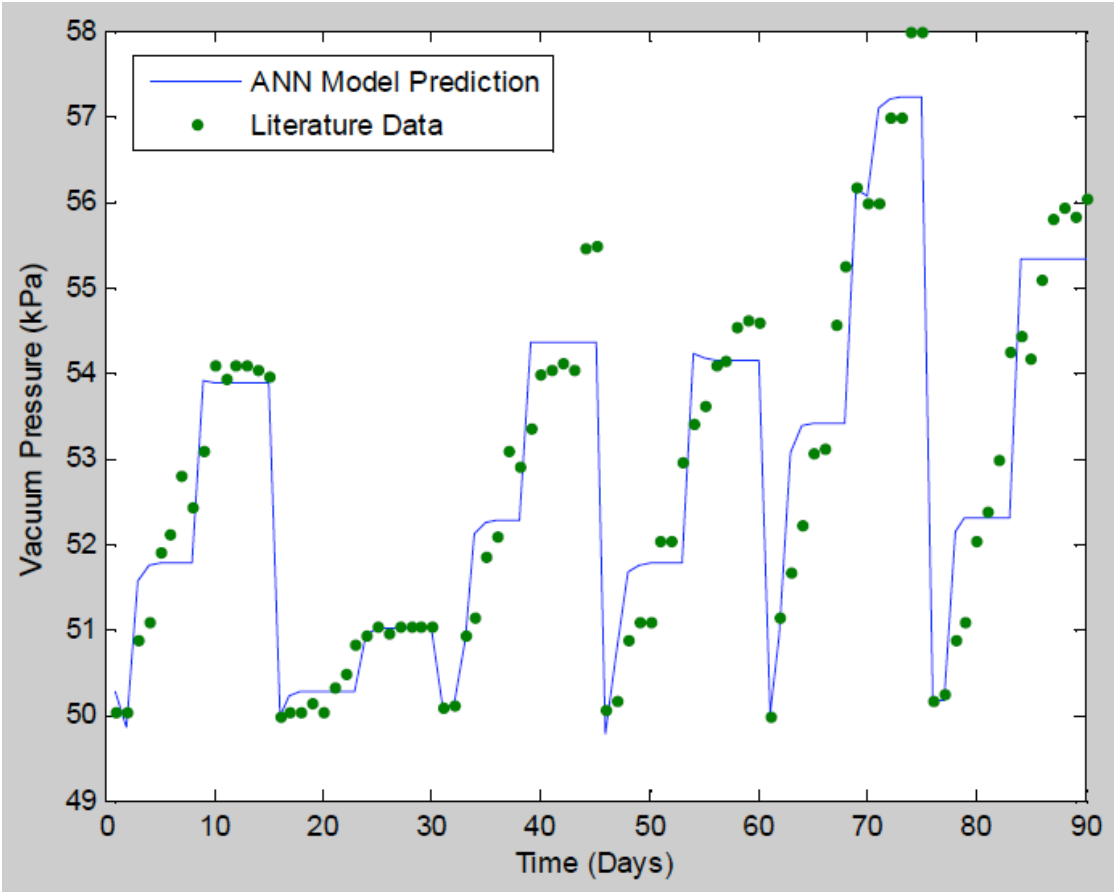

Figure 6: ANN predicted and experimental $P_{\text {vac }}$ of ANN2 - scenario 1.

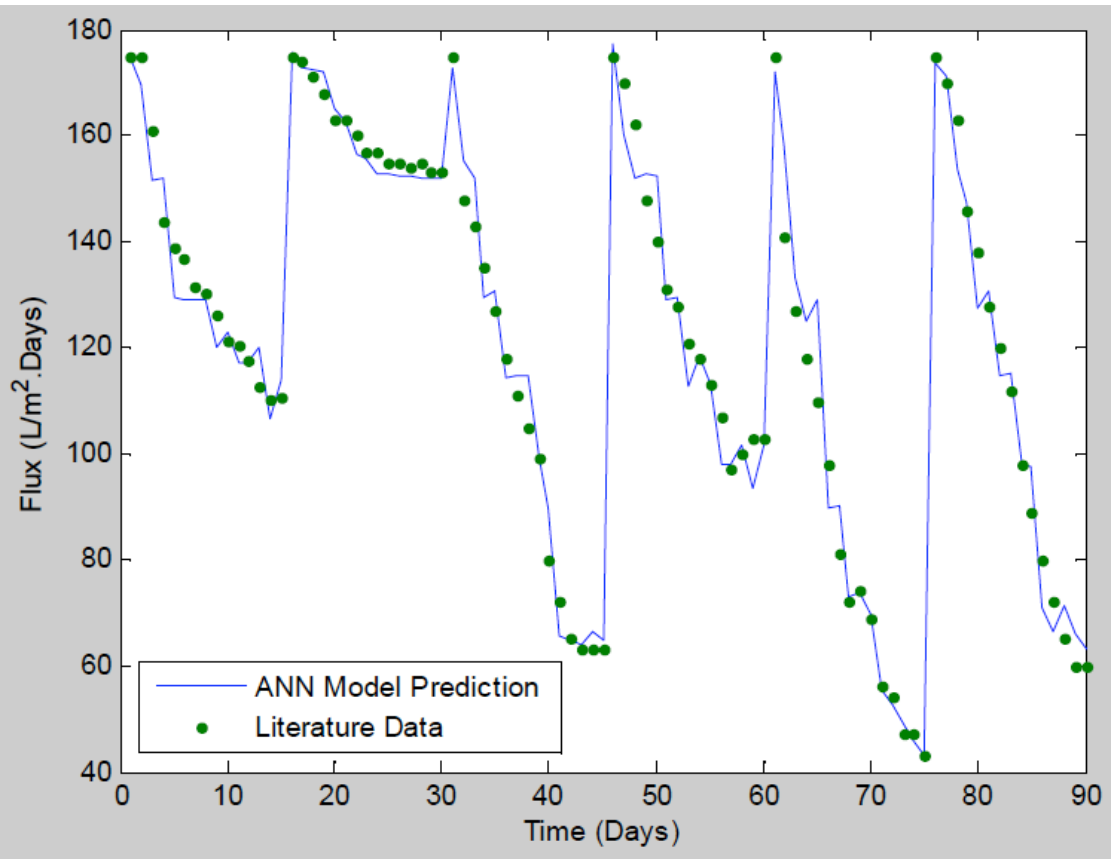

Figure 7: ANN predicted and experimental flux of ANN3 - scenario 1. 
(Figure 5), vacuum pressure (Figure 6) and flux (Figure 7).

\section{ANN Scenario 2}

The objective is to obtain an ANN model between the ratio and flux (Single Input-Single Output, SISO). ANN trains the vacuum-to-backwash time ratio (input variable) to directly predict the flux (output variable), see Figure $\mathbf{8}$. The training is performed by minimizing the error between the predicted flux from ANN and the experimental flux (target variable). ANN training is stopped utilizing 74 epochs. The predicted flux from ANN model is validated with that obtained experimentally in Figure 9. The overall regression between the ANN predicted output and target is found with training, validation, and testing regressions of $0.921,0.924$, and 0.924 , respectively. As shown in Figure 9, the ANN model for scenario two was able to capture most of the data points and gives reasonable match with actual process dynamics but not as good as scenario one ANN model predictions shown in Figure 7.

\section{ANN Scenario 3}

The objective is to obtain an ANN model between all the three input variables:

- $\quad$ Inputs

1) Ratio

2) Backwash pressure, $P_{b w}$

3) Vacuum pressure, $P_{\text {vac }}$

\section{- $\quad$ Output: flux}

As a result a multi-input-single-output (MISO) ANN is performed as shown in Figure 10. ANN trains all three inputs to predict the flux (output variable). The training is performed by minimizing the error between the predicted flux from ANN and the experimental flux (target variable). ANN training is stopped utilizing 40 epochs. The predicted flux from ANN model is validated with that obtained experimentally as shown in Figure 11. The overall regression between the ANN predicted output and target with training, validation, and

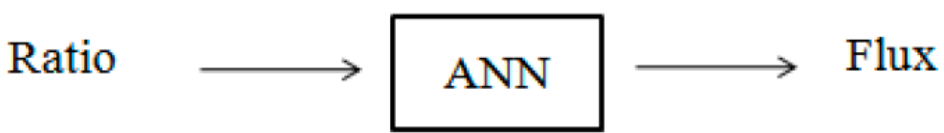

Figure 8: ANN model diagram for SISO system - scenario 2.

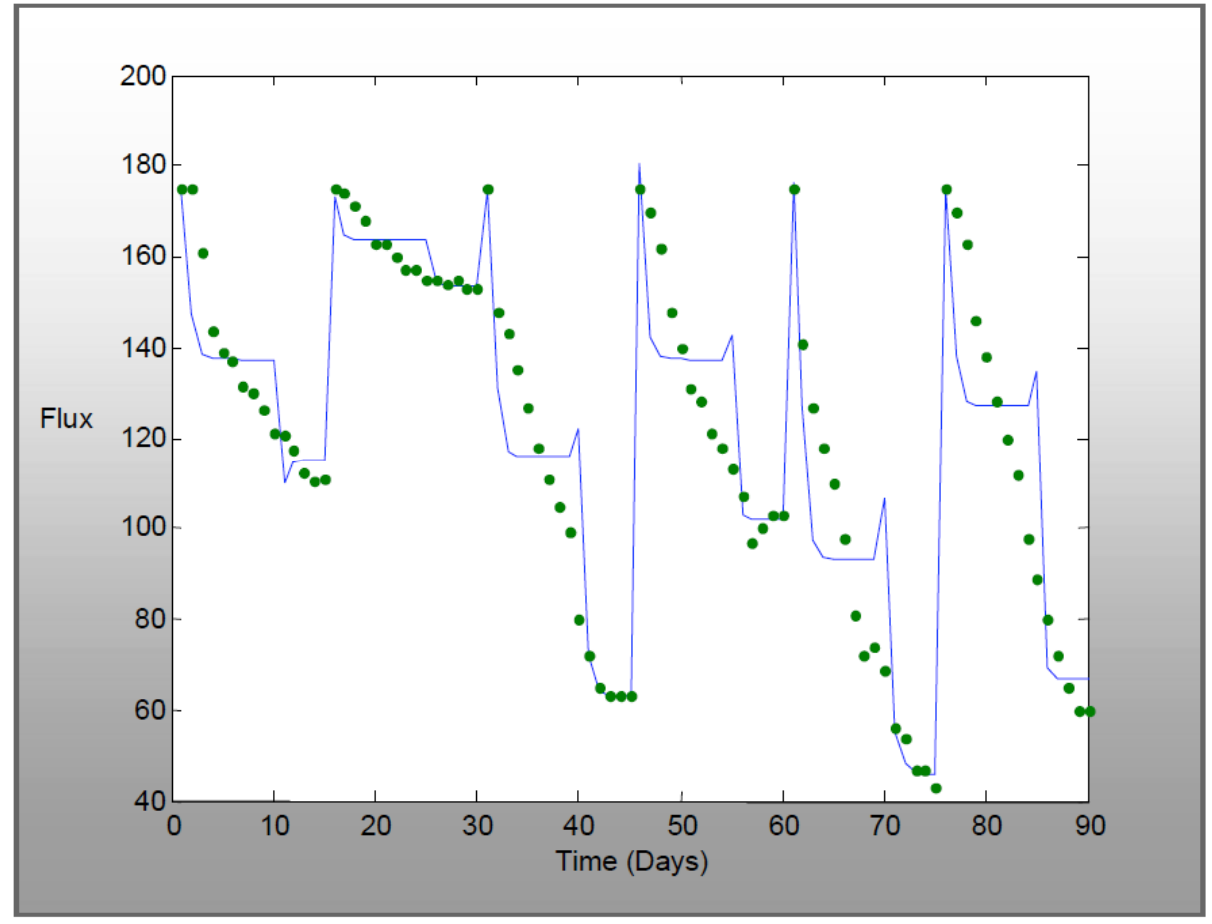

Figure 9: ANN predicted and experimental flux - scenario 2. 


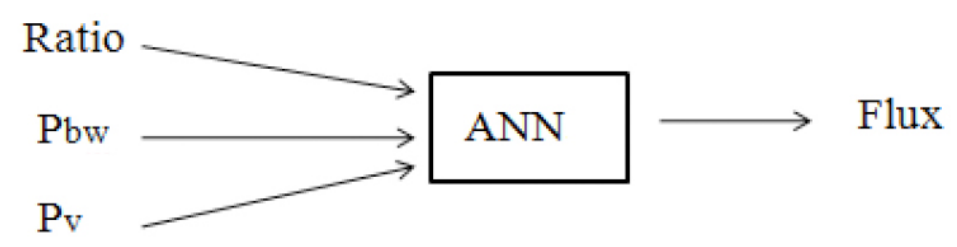

Figure 10: ANN model diagram for the MISO system - scenario 3.

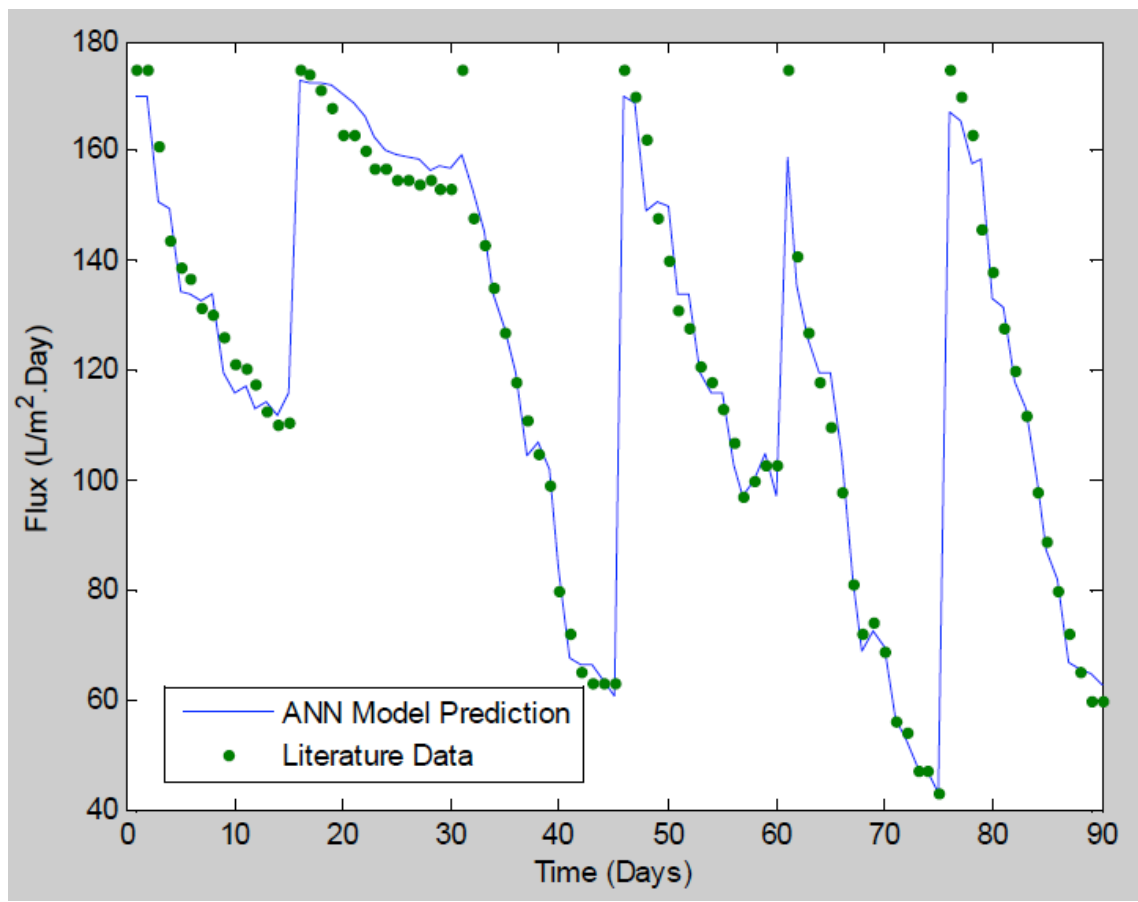

Figure 11: ANN predicted and experimental flux - scenario 3.

testing regressions of $0.991,0.990$, and 0.990 , respectively. As all three inputs were considered in this structure, the ANN model predictions were more accurate than previous scenario 2 and gives comparable match with scenario 1 . Therefore, the ANN model in scenario 3will be considered in the dynamic sensitivity analysis. However, scenario 2 ANN model structure will be re-identified and used in the NN-MPC control system design as it has a SISO structure.

Sensitivity analysis was performed to determine the effects of variations in the process inputs on the process output. The ANN model developed above was used to study the flux response to step changes in each process input. The sensitivity analysis was performed by changing one of the input variables while maintaining the other input variables constant. There after, we observed and recorded the ANN model prediction of the output variable response. Furthermore, the input variables step change was performed within a specific range of each input. The range was set within the upper and lower limits of the experimental data that were used to train the ANN model. Figure 12 shows the SIMULNK block diagram of the sensitivity analysis applied to the ANN model developed above for the MBR. The response of the flux was studied by applying a step change on the three process inputs including the backwash pressure, vacuum pressure, and vacuum-to-backwash time ratio. First the flux response was studied with respect to changes in the backwash pressure. The backwash pressure range was between $90-96 \mathrm{kPa}$ and was obtained from Aidan et al. [15]. The vacuum pressure was maintained at $50 \mathrm{kPa}$ and the ratio was maintained at 10 minutes vacuum time to 2 minutes backwash time. Figure 13 shows the variation of the flux with respect to changes in backwash pressure at a constant vacuum pressure and vacuum-to-backwash-time ratio.

A similar procedure was followed for both the vacuum pressure and the ratio of vacuum-to-backwash time. The vacuum pressure range was set between 50.0 - $58.0 \mathrm{kPa}$, while the backwash pressure was upheld at $92.4 \mathrm{kPa}$.Theratio was maintained at 10 


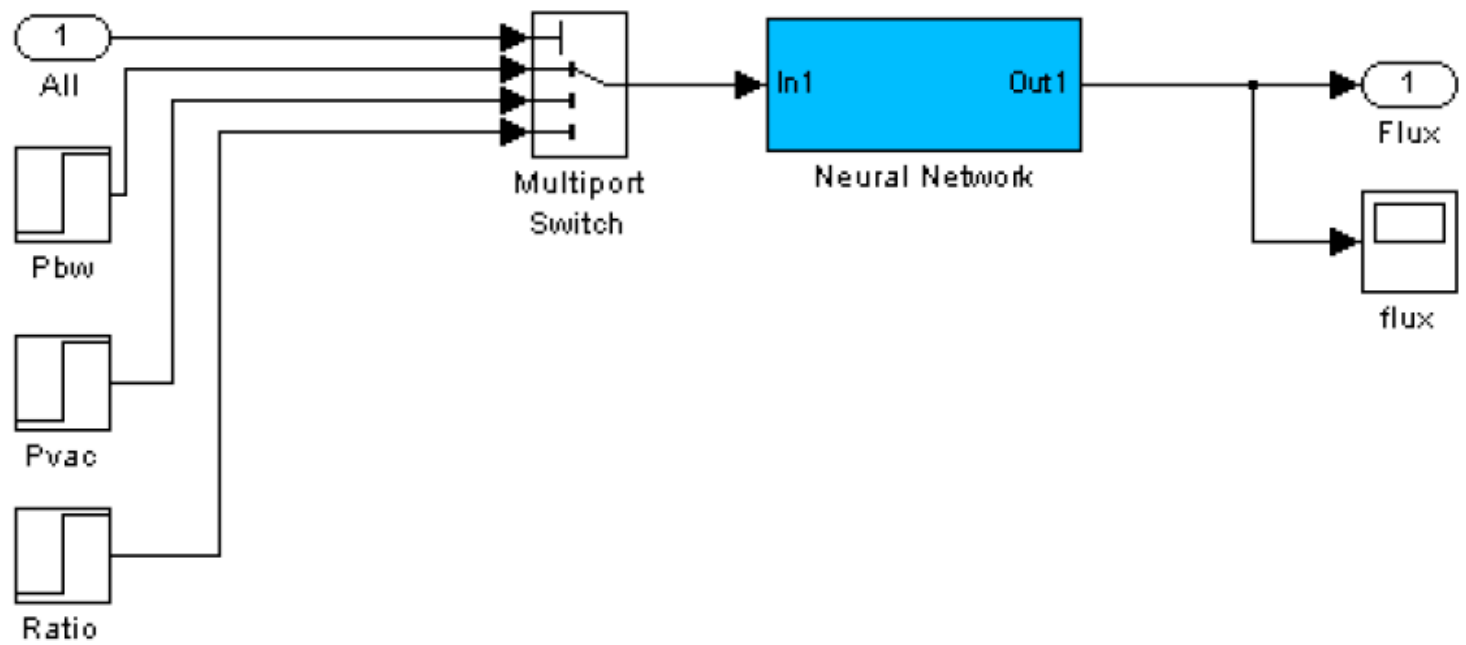

Figure 12: SIMULINK ANN block diagram for sensitivity analysis.

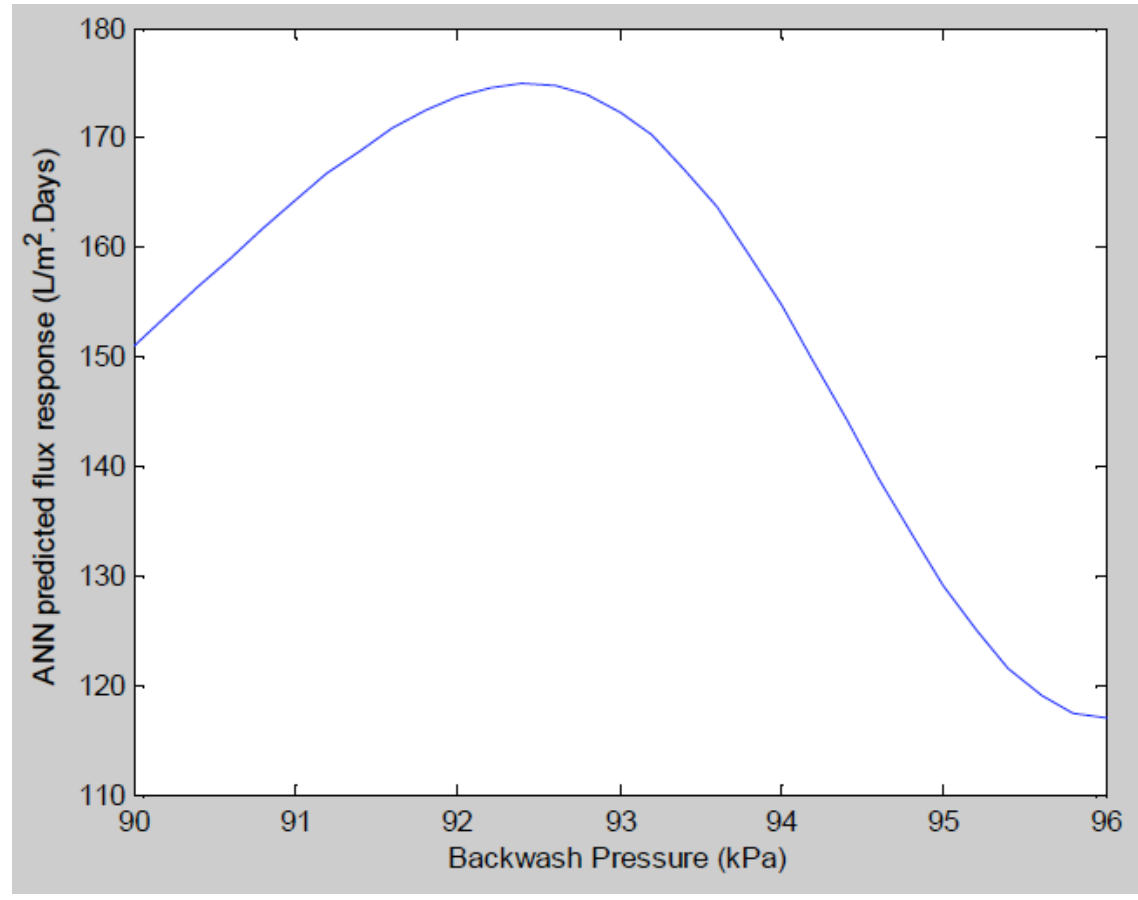

Figure 13: ANN predicted flux response due to backwash pressure step change.

minutes vacuum to 2 minutes backwash. The ratio range was set between $4.7-33$, while the backwash pressure was maintained at $92.4 \mathrm{kPa}$, and the vacuum pressure was sustainedat $50 \mathrm{kPa}$. Figures 14 and 15 demonstrate the flux behavior as a result of changes in the vacuum pressure and ratio, respectively. Figure $\mathbf{1 3}$ indicates that as the backwash pressure increases, the flux increases to a maximum point and then decreases. The maximum flux was observed at $175\left(\mathrm{~L} / \mathrm{m}^{2}\right.$.day $)$ corresponding to a backwash pressure of $92.4 \mathrm{kPa}$. This behavior may be explained as follows: as the backwash pressure increases, a better fouling removal is attained and enhances the flux behavior. However, further increases of the backwash pressure may rupture the membrane and inversely affect the membrane filtration performance. Figure $\mathbf{1 4}$ demonstrates the flux behavior versus vacuum pressure changes. The maximum flux was obtained at the lowest vacuum pressure. The lowest vacuum pressure occurred at the highest filtration or operation pressure. The maximum flux was obtained at 175 $\left(\mathrm{L} / \mathrm{m}^{2}\right.$.day $)$ and corresponded to a vacuum pressure range between $50-51 \mathrm{kPa}$. Beyond this range, a sharp flux decline was observed with increasing the vacuum pressure. Similarly, the maximum flux was obtained at the lowest vacuum-to-backwash time ratio, 


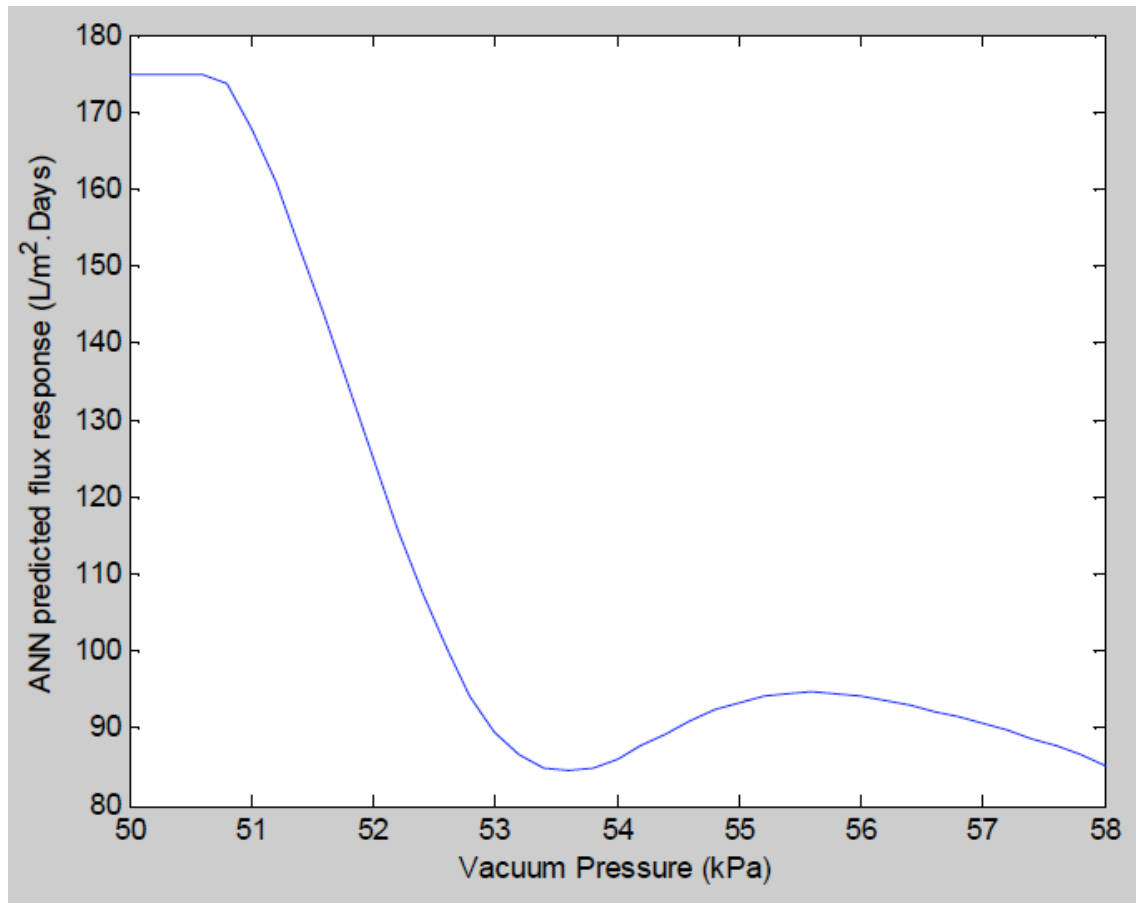

Figure 14: ANN predicted flux response due to vacuum pressure step change.

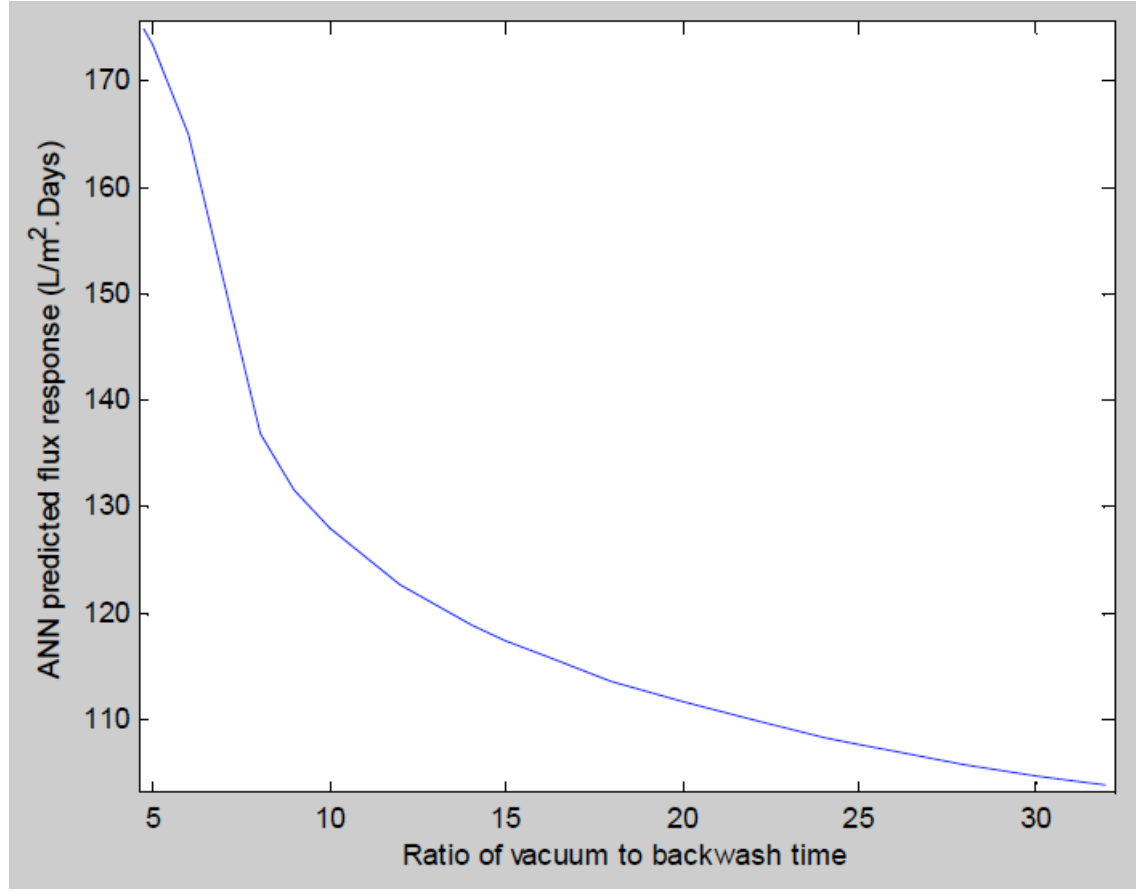

Figure 15: ANN predicted flux response due to ratio of vacuum-to-backwash time step change.

as demonstrated in Figure 15. The low ratio indicated operating with a long, but less frequent, backwash time. The maximum flux was $175\left(\mathrm{~L} / \mathrm{m}^{2}\right.$.day) and corresponded to a vacuum-to-backwash time ratio range between 4.7 and 5.1 .

The backwash scheduling (vacuum-to-backwash time ratio) was further investigated using SIMULINK.
Specifically, we investigated the flux response corresponding to step changes in vacuum time and backwash time. Each input variable was manipulated while the other input variable was fixed. The flux behavior exhibiteda sharp increase to a maximum followed by a gradual decline as the ratio increased, Figure 16. Increasing the ratio indicated longer operation or vacuum duration as opposed to less 


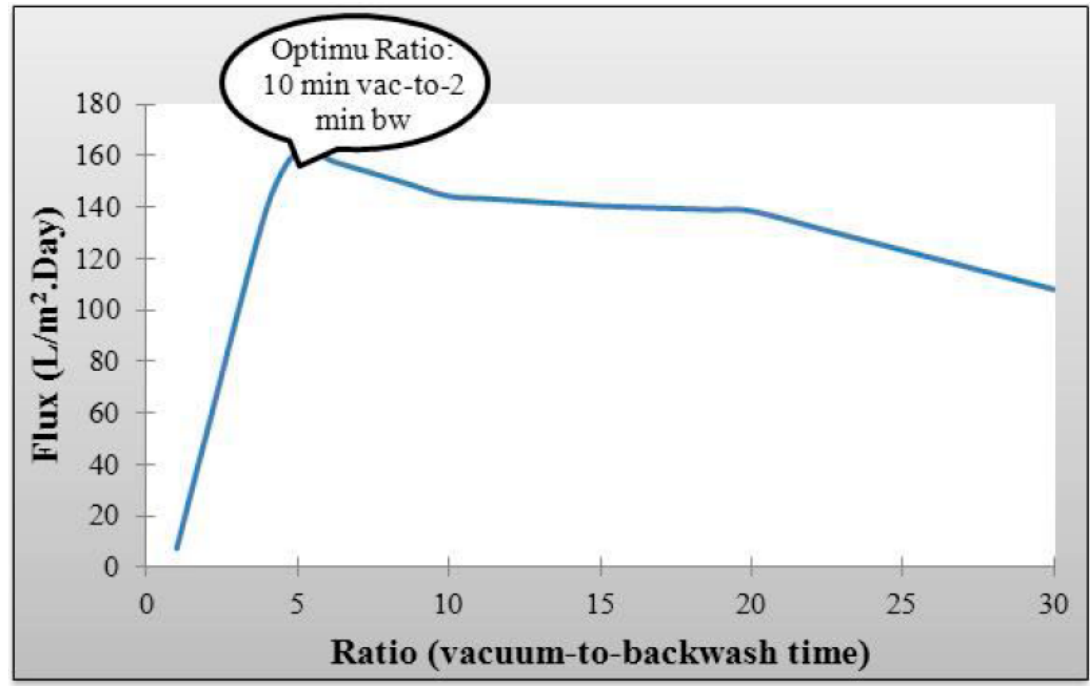

Figure 16: Optimum backwash scheduling.

frequent backwash. The maximum flux was attained at around $165\left(\mathrm{~L} / \mathrm{m}^{2}\right.$.day $)$ that corresponded to an optimum vacuum-to-backwash time ratio of 10 minutes vacuum to 2 minutes backwash. The results are consistent with the ones shown in Figure 14 and hence verified the optimum backwash scheduling.

The behavior of the flux shown in Figure $\mathbf{1 6}$ may be attributed to the backwash duration. The left region of the figure shows a comparable backwash to vacuum duration. In contrast, the right region shows a higher vacuum to backwash duration. For example, at a ratio of one, the backwash is equal to the vacuum duration. Thus, an unstable process operation is attained due to the frequent switching of operation between vacuum and backwash. As a result, a rapid flux decline is observed indicating severe membrane fouling. On the other hand, the right region represents a prolonged vacuum duration as opposed to backwash durations; therefore, membrane fouling is represented by the gradual flux decline.

A new and larger set of data was generated using the ANN model developed in scenario 2 outlined above. The generated data were trained using Levenberg-Marquardt learning algorithm with 200 epochs. A summary of the ANN model architecture and data set is given in Table 1 . The ratio (manipulated input variable) was constrained between the minimum and maximum value obtained from the experimental data; corresponding to a minimum ratio of 10 minutes vacuum to 2 minutes backwash and a maximum ration of 30 minutes vacuum to 1 minute backwash.

Once the neural network is trained, plant identification is completed and the next step is to tune the controller parameters. The NN-MPC parameters define the aggressiveness of the controller; nevertheless, a more aggressive controller performance is a trade-off between stability and computational speed. As such, a more stable controller performance is attained at longer horizons. Yet, this requires more computational time and hence, slower controller response (i.e. less aggressive controller). Tuning of the controller parameters was performed following the above mentioned guidelines. Thereafter, the NN-MPC parameters were further adjusted by performing several simulations to attain the optimum set-point tracking. The optimum NN-MPC parameters are summarized in Table 2. The set-point was provided by the NN-MPC MATLAB/SIMULINK signal builder block. The signal range was set between 50 and 120 $\left(\mathrm{L} / \mathrm{m}^{2}\right.$.days) with pulse duration of 200 sampling time. The controlled variable (i.e. flux) response in tracking

Table 1: ANN Model Structure Specifications

\begin{tabular}{|c|c|}
\hline ANN type & Multi-layer feed forward \\
\hline \hline $\begin{array}{c}\text { Number of layers } \\
\text { (input, hidden, output) }\end{array}$ & 3 \\
\hline Number of Neurons in: \\
Input layer \\
Hidden layer & 1 \\
Output layer & 20 \\
\hline Activation function in: \\
Input layer \\
Hidden layer \\
Output layer
\end{tabular}


Table 2: NN-MPC Parameters

\begin{tabular}{|c|c|}
\hline Prediction Horizon & 8 \\
\hline Control Horizon & 4 \\
\hline Control weighting factor & 0.1 \\
\hline Search factor & 0.1 \\
\hline
\end{tabular}

the set-point changes is shown in Figure 17. The manipulated variable (i.e. vacuum-to-backwash time ratio) changes within the constrained range are depicted in Figure 18. The results indicated that a reliable controller performance was achieved in terms of set-point tracking with no oscillations. The controller was able to drive the process variable to track the setpoint pulse changes in both directions (increasing/decreasing). Furthermore, a fast process variable response in tracking the set-point was observed. Yet, a slower response was observed at the highest flux (i.e. $120 \mathrm{~L} / \mathrm{m}^{2}$.days), but ultimately the setpoint was achieved with no overshoot. Nevertheless, the maximum flux (i.e. $175 \mathrm{~L} / \mathrm{m}^{2}$.day) was not achieved due to the NN-MPC constraints. As illustrated in Figure 18, the input reached saturation range at the corresponding flux of $120\left(\mathrm{~L} / \mathrm{m}^{2} \cdot\right.$ day $)$.

\section{CONCLUSIONS}

The ANN was able to capture the dynamic behavior of the MBR process and provided an accurate

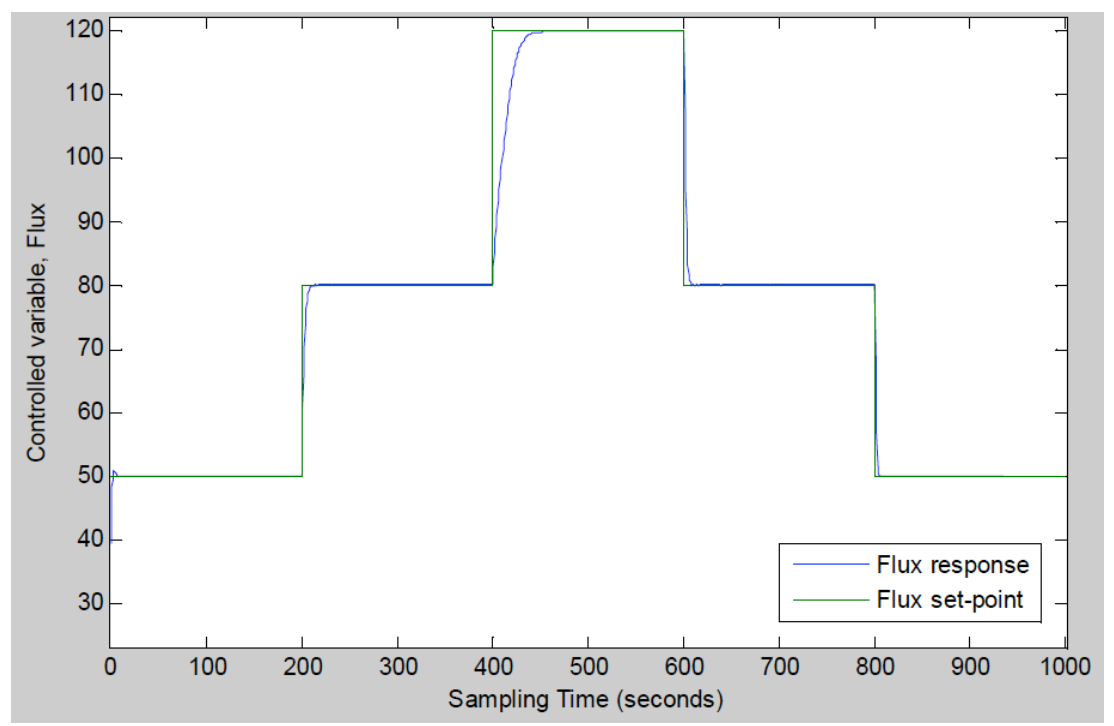

Figure 17: Flux output response with NN-MPC for tracking flux set-point changes.

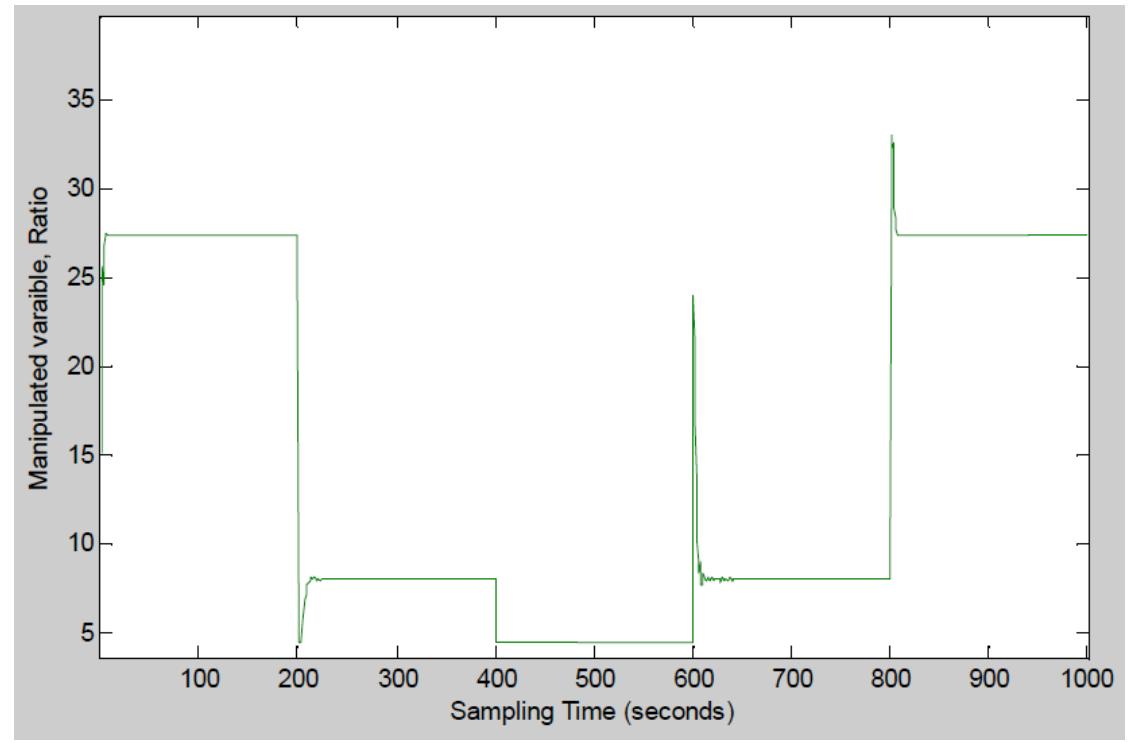

Figure 18: Variation of vacuum-to-backwash time ratio (control input moves) in response to flux set-point changes with NNMPC. 
prediction of the process output flux in less computational time. Sensitivity analysis revealed the effect of the backwash pressure, vacuum pressure, and ratio of vacuum-to-backwash time on membrane fouling in MBR. The maximum flux was observed at $175\left(\mathrm{~L} / \mathrm{m}^{2}\right.$.day) corresponding to a backwash pressure of $92.4 \mathrm{kPa}$ and a vacuum pressure range between 50 - $51 \mathrm{kPa}$. An optimum ratio of 10 minutes vacuum to 2 minutes backwash was obtained for scheduling the MBR operation. Such operation resulted in slower flux decline due to efficient removal of foulants as it has been verified experimentally in a previous work.

The ANN model was successfully employed in the advanced neuro-model predictive control (NN-MPC). The NN-MPC control mechanism demonstrated excellent servo response characteristics in tracking pulse set-point changes of flux subject to constrains in the manipulated variable (vacuum-to-backwash time ratio). The adaptive structure of the NN-MPC rendered implementation of fouling control via backwash scheduling in MBR process to be feasible.

\section{REFERENCES}

[1] Kim MJ, Sankararao B, Yoo CK. Determination of MBR fouling and chemical cleaning interval using statistical methods applied on dynamic index data. J Membr Sci 2011; 375: 345-53.

http://dx.doi.org/10.1016/j.memsci.2011.04.001

[2] Pierre LC, Vicki C, Tony A. Fouling in membrane bioreactors used in wastewater treatment. J Membr Sci 2006; 284: 1726.

http://dx.doi.org/10.1016/j.memsci.2006.08.019

[3] Chang IS, Clech PL, Jeffersom B, Judd S. Membrane fouling in membrane bioreactors for wastewater treatment. J Environ Technol 2002; 11: 1018-29.

[4] Huyskens C, Brauns E, Van HE, Wever DH. A new method for the evaluation of the reversible and irreversible fouling propensity of MBR mixed liquor. J Membr Sci 2008; 323: 185-94.

http://dx.doi.org/10.1016/j.memsci.2008.06.021

[5] Liu QF, Kim SH. Evaluation of membrane fouling models based on benchscale experiments: a comparison between constant flow rate blocking laws and artificial neural network (ANNs) model. J Membr Sci 2008; 310: 393-401. http://dx.doi.org/10.1016/j.memsci.2007.11.020

[6] Vargas A, Moreno-Andrade I, Buitro G. Controlled backwashing in a membrane sequencing batch reactor used for toxic wastewater treatment. J Membr Sci 2008; 320: 18590. http://dx.doi.org/10.1016/j.memsci.2008.03.073

Smith PJ, Vigneswaran S, Ngo HH, Ben-Aim R, Nguyen H. A new approach to backwash initiation in membrane systems. J Membr Sci 2006; 278: 381-89.

http://dx.doi.org/10.1016/j.memsci.2005.11.024

[8] Rahmanian B, Pakizeh M, Esfandyari M, Heshmatnezhad F, Maskooki A. Fuzzy modeling and simulation for lead removal using micellar-enhanced ultrafiltration (MEUF). J Hazardous Mater 2011; 192: 585-92.

http://dx.doi.org/10.1016/j.jhazmat.2011.05.051
[9] Busch J, Marquardt W. Model-based control of MF/UF filtration processes: pilot plant implementation and results. Water Sci Technol 2009; 59(9): 1713-20. http://dx.doi.org/10.2166/wst.2009.648

[10] Bowen W, Jones MG, Welfoot JS, Yousef H. Predicting salt rejections at nanofiltration membranes using artificial neural networks. Desalination 2000; 129(2): 147-62. http://dx.doi.org/10.1016/S0011-9164(00)00057-6

[11] Rostamizadeh M, Rizi SM. Predicting gas flux in silicalite-1 zeolite membrane using artificial neural networks. J Membr Sci 2012; 403: 146-51. http://dx.doi.org/10.1016/j.memsci.2012.02.036

[12] Abbas A, Al-Bastaki N. Modeling of an RO water desalination unit using neural networks. Chem Eng J 2005; 114: 139-43. http://dx.doi.org/10.1016/j.cej.2005.07.016

[13] Aydiner C, Demir I, Keskinler B, Lnce O. Joint analysis of transient flux behaviors via membrane fouling in hybrid PAC/MF processes using neural network. Desalination 2009; 250: 188-96.

http://dx.doi.org/10.1016/..desal.2009.06.025

[14] Yu DL, Gomm JB. Implementation of neural network predictive control to a multivariable chemical reactor. Control Eng Pract 2003; 11: 1315-23. http://dx.doi.org/10.1016/S0967-0661(02)00258-7

[15] Aidan A, Abdel-Jabbar N, Ibrahim T, Nenov V, Mjalli F. Neural network modeling and optimization of scheduling backwash for membrane bioreactor. Clean Technol Environ Policy 2007; 10(4): 389-95. http://dx.doi.org/10.1007/s10098-007-0129-0

[16] Comas J, Meabe E, Sancho L, Ferrero G, Sipma J, Monclus $\mathrm{H}$, Rodriguez-Roda I. Knowledge-based system for automatic MBR control. Water Sci Technol 2010; 62(12): 2829-36. http://dx.doi.org/10.2166/wst.2010.693

[17] Fatone F, Battistoni P, Bolzonella D, Pavan P, Checchi F. Long-term experience with an automatic process control for nitrogen removal in membrane bioreactors. Desalination 2008; 227: 72-84.

http://dx.doi.org/10.1016/i.desal.2007.05.036

[18] Ferrero G, Monclu SH, Buttiglieri G, Comas J, RodriguezRoda I. Automatic control system for energy optimization in membrane bioreactors. Desalination 2011; 268: 276-80. http://dx.doi.org/10.1016/j.desal.2010.10.024

[19] Ferrero G, Monclu SH, Buttiglieri G, Comas J, RodriguezRoda I. Development of a control algorithm for air scour reduction in membrane bioreactors for wastewater treatment. J Chem Technol Biotechnol 2011; 86(6): 784-89. http://dx.doi.org/10.1002/jctb.2587

[20] Ferrero G, Monclu SH, Buttiglieri G, Comas J, RodriguezRoda I. A knowledge-based control system for air scour optimization in membrane bioreactors. Water Sci Technol 2011; 63(9): 2025-31. http://dx.doi.org/10.2166/wst.2011.455

[21] Huyskens C, Brauns E, Van Hoof E, Diels E, De Wever H Validation of a supervisory control system for energy saving in membrane bioreactors. Water Res 2011; 45: 1443-53. http://dx.doi.org/10.1016/j.watres.2010.11.001

[22] Madyastha VK, Prasad V, Mahendraker V. Reduced order model monitoring and control of a membrane bioreactor system via delayed measurements. Water Sci Technol 2011; 64(8): 1675-84. http://dx.doi.org/10.2166/wst.2011.437

[23] Maere T, Verrecht B, Moerenhout S, Judd S, Nopens I. BSMMBR: a benchmark simulation model to compare control and operational strategies for membrane bioreactors. Water Res 2011; 45(6): 2181-90. http://dx.doi.org/10.1016/j.watres.2011.01.006

[24] Seborg DE, Edgar TF, Mellichamp DA, Doyle FJ. Process Dynamics and Control.3rd edition, John Wiley \& Sons, New York 2010. 
[25] Bequette BW. Process Control: Modeling, Design and Simulation. Prentice Hall, New Jersey, USA 2003.

[26] Shilnikov LP, Shilnikov AL, Turaev DV, Chua LO. Methods of qualitative theory in nonlinear dynamics. World Scientific 1998.

http://dx.doi.org/10.1142/9789812798596

[27] Galluzzo M, Cosenza B. Control of the biodegradation of mixed wastes in a continuous bioreactor by type-2 fuzzy logic controller. Comp Chem Eng 2008; 33: 1475-83.

http://dx.doi.org/10.1016/j.compchemeng.2009.04.003
[28] Qin SJ, Badgwell TA. An overview of industrial model predictive control technology. Proc. Fifth International Conference on Chemical Process Control, AIChE/CACHE 1997.

[29] Alnaizy R, Abdel Jabbar N, Aidan A, Abachi N. Modeling and dynamic analysis of a membrane bioreactor with backwash scheduling. Desalination Water Treat 2012; 41: 186-94. http://dx.doi.org/10.1080/19443994.2012.664713

[30] MATLAB NN Predictive Control, Control Systems: Neural Network Toolbox, Natick, MA, USA 2012.

(C) 2013 Alnaizy et al.; Licensee Lifescience Global.

This is an open access article licensed under the terms of the Creative Commons Attribution Non-Commercial License (http://creativecommons.org/licenses/by-nc/3.0/) which permits unrestricted, non-commercial use, distribution and reproduction in any medium, provided the work is properly cited. 